\title{
Inserted During a Non-Percutaneous Coronary Intervention
}

National Cancer Institute

\section{Source}

National Cancer Institute. Inserted During a Non-Percutaneous Coronary Intervention.

NCl Thesaurus. Code C99962.

Mechanical Circulatory Support was inserted during a non-Percutaneous Coronary

Intervention $(\mathrm{PCl})$ procedure. (ACC) 